\title{
Efficacy and efficiency of fracture liaison services to reduce the risk of recurrent osteoporotic fractures
}

\author{
M. K. Javaid ${ }^{1}$ (D)
}

Received: 29 September 2020 / Accepted: 19 March 2021 / Published online: 28 May 2021

(c) The Author(s) 2021

\begin{abstract}
Background Acting to prevent the next fracture after a sentinel fracture is support by the evidence base and brings benefits for patients, clinicians and healthcare systems. However, more patients after a fragility fracture remain untreated and vulnerable to future potentially life-changing fractures. Fracture liaison services (FLS) are models of care that can close this care gap. Methods A narrative review of the key evidence for the efficacy and effectiveness of FLS was performed

Results There are few randomised control trials of FLSs and none with fracture as the primary outcome. Several observational studies have also demonstrated reductions in fracture, but most were limited by potential bias. Several studies have highlighted that not every FLS is automatically effective.

Conclusion Further research should focus on implementing effective FLS using published standards and only then exploring impacts on patient outcomes such as refracture rates.
\end{abstract}

Keywords Fracture liaison service · Osteoporosis · Quality improvement

\section{Introduction}

A fragility fracture is a significant event for patients and their family, leading to a substantial loss of quality of life and an increase in mortality [1]. Fragility fractures are a recognised significant risk factor for further fractures $[2$, 3]. Healthcare systems are now beginning to recognise the benefits of secondary fracture prevention [4] and prioritise secondary fracture prevention above primary prevention and fall prevention, where the return on investment of healthcare resources may be less. Despite effective treatments to reduce fracture risk, less than $50 \%$ of patients receive effective secondary fracture prevention after a fragility fracture $[5,6]$. To address this care gap, several initiatives have been published to improve clinical services by implementing fracture liaison services (FLSs) [7-14]. Initiated in the 1990s by Drs McLellan [15] and Gallacher [16], an FLS works is a team of healthcare professionals that systematically identifies, investigates, recommends treatment and then monitor

M. K. Javaid

Kassim.javaid@ndorms.ox.ac.uk

$1 \quad$ Nuffield Department of Orthopaedics, Rheumatology and Musculoskeletal Sciences, University of Oxford, Oxford, UK patients to optimise adherence to evidence-based interventions to reduce fracture risk (Fig. 1) [17]. The International Osteoporosis Foundation was the first international organization that capitalized on FLS through its very comprehensive Capture the Fracture programme, launched in 2012. Several hybrid service solutions such as Osteoporosis Liaison Services (OLS), orthogeriatric services (OGS) have since evolved and fit into the broad category of Post Fracture Care (PFC) services, of which FLS is an example.

\section{Efficacy of FLS}

Large scale randomised trials have demonstrated the clinical effectiveness of anti-osteoporosis medication to reduce fracture risk significantly [18-25]. Further, analyses of routine health data have demonstrated the potential for anti-osteoporosis medications to reduce fracture risk in the real-world setting [26]. The scale of fracture reduction depends on the fracture site with the most significant reductions seen for vertebral fractures, then hip and non-spine/nonvertebral fracture sites [27]. Translating these benefits to an FLS setting depends on many factors. The first step is an identification strategy enriched for patients at moderate or high risk. This may include using age thresholds, such as over 50,65 - or 75 -year-olds or sites 
Fig. 1 Key components of an FLS

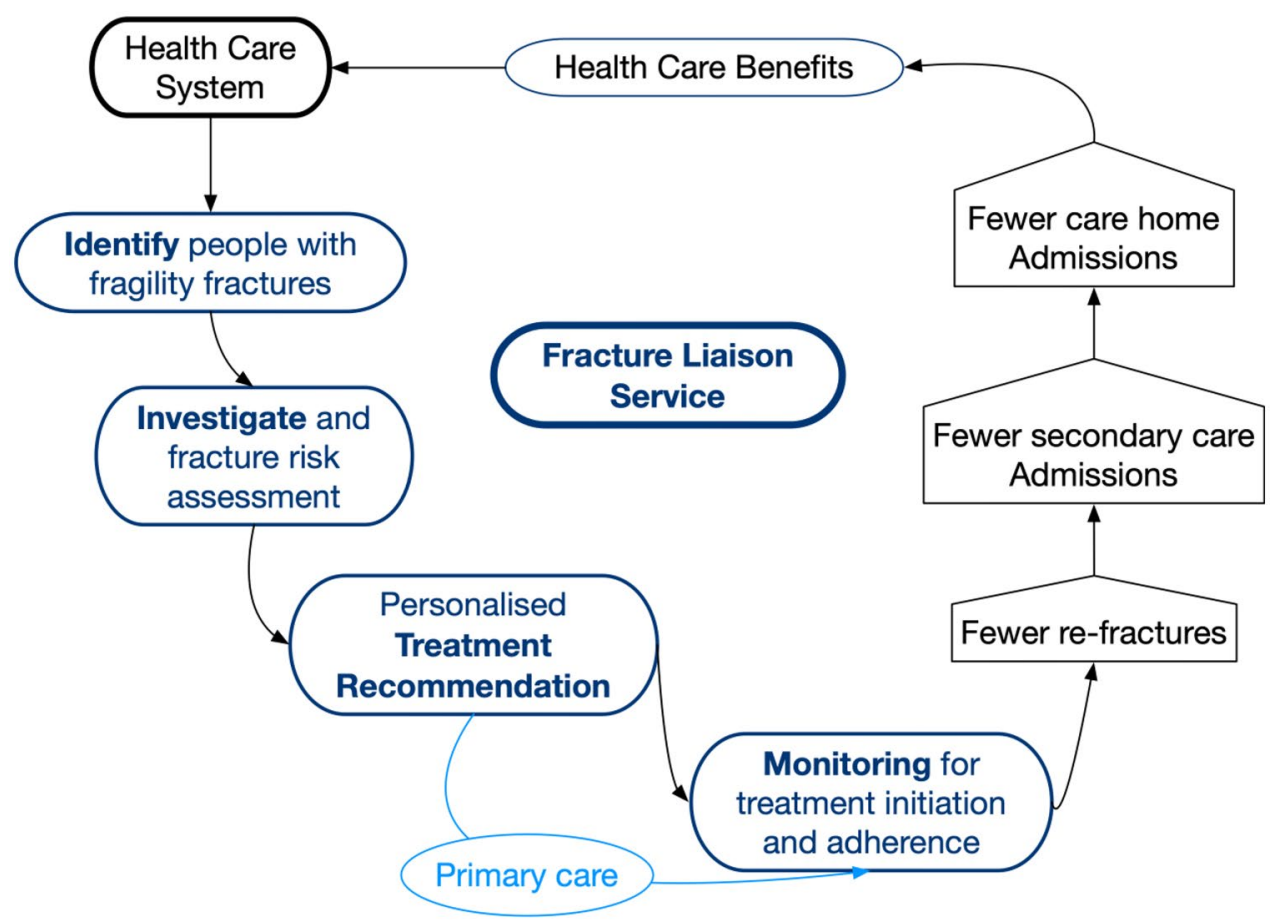

of fracture, such as the hip, spine, femur, humerus, pelvis and ribs. The objective is to find enough moderate/high-risk patient and fewer low-risk patient who after assessment, do not qualify for treatment. The relevance of the level of trauma for case-finding has been challenged by the evidence that patients with fractures from high trauma are at greater risk of future osteoporotic fractures [28], BMD is low in patients who have fractures after major trauma injuries [29] and anti-osteoporosis medications reduce fracture after simple falls as well as after high-trauma injuries [30]. Most guidelines would exclude fracture of the scaphoid, face, skull and digits. Inclusion of ankle and metatarsal/metacarpal fractures could be considered after evidence that identification of higher risk fracture sites has been optimised.

The second step is ensuring that patients identified by the FLS are assessed rapidly so eligible patients are recommended specific anti-osteoporosis therapy that reflects their baseline risk of fracture. After a sentinel fracture, the risk of refracture is high [31], and up to $50 \%$ of the 10 year risk is compressed into the first two years post-fracture [32], the imminent fracture risk [33]. Different anti-osteoporosis treatments have differing relative potencies [34, 35] as well as time to onset [36]. This evidence needs to be in balance with national reimbursement when personalising treatment recommendations. The third step is ensuring eligible patients who are recommended AOM, start them promptly, given the potential delay between treatment onset and benefit [36], and adhere.

\section{Effectiveness of FLSs}

To date, no randomised control trials have demonstrated the superiority of FLS in reducing fracture risk, the primary outcome of a service.

Clinical trials with surrogate outcomes such as DXA testing and treatment initiation and adherence in this area were led by the late S.Majumdar. His team demonstrated increases in diagnosis and post-fracture treatment in series of randomised controlled trials with blinded ascertainment of outcome in adults with upper limb fractures in the emergency room setting, [37, 38]. Disappointingly, longer term follow-up demonstrated an unexpected lower adherence to therapy at 24 months, highlighting the need for adequate follow-up for FLSs [39]. Limitation of these trials include exlusion of patients with cognitive impairment or patients requiring inpatient care, limiting generalisability.

Randomised trials may be considered inappropriate given the lack of equipoise that FLS are effective from policy, clinical and patient perspectives. Further, FLS trials would likely need to be cluster randomised to limit contamination within sites and for recruited sites to agree not to initiate an FLS during the trial duration, even within a step wedge design. The estimated sample size to demonstrate a $25 \%$ reduction in refractures at 2 years with an expected refracture rate of $12 \%$ would exceed 15,000 participants using a cluster design and take over 4 years to deliver, challenging the value of information of such research. Finally, an FLS is a complex intervention requiring multiple levels of 
engagement within the existing healthcare systems and has to adapt to changes in local and national changes in health delivery as well as the availability of new AOMs. Ensuring intervention fidelity would be difficult.

Given the challenges for running clinical trials, observational studies have been used to examine the effectiveness of FLSs. There are three broad types of study. The most typical method is to compare differences in fracture rates before and after the introduction of a fracture prevention service. One of the first studies was from the South California S Permanente, USA. The introduction of the Kaiser model led to a $37 \%$ reduction in hip fracture rates and an associated $\times 2-6$ increase in DXA rates and prescribing rates [40]. However, there was no contemporaneous control arm and only three pre-intervention data points to model the expected exponential fracture rate trajectory accurately. In terms of the intervention, the Kaiser secondary fracture prevention model required an integrated information system linking hospital admissions, primary care physician visits, bone density scanning and pharmacy dispensing to case find, assess, initiate and detect discontinuation and included primary prevention, which limits generalisability. To overcome the issue of contemporary controls, an interrupted time series of analysis compared outcomes across 11 healthcare centres in the UK that introduced orthogeriatric and FLS services at different time points to try to overcome the issue of secular trends [41]. While a significant reduction in mortality was demonstrated, no effect on refracture rates was seen with almost 34,000 sentinel hip fractures. A significant limitation of this study was the FLS interventions typically did not include a monitoring component [42]. The Ontario Fracture Clinic screening program also used an interrupted time series methodology to compare BMD testing, treatment initiation and adherence 1 year after fracture across in hospitals with a PFC program and non-intervention hospitals [43]. From 147,071 individuals with an index fracture, BMD testing improved from $17 \%$ pre-intervention to $20.9 \%$ post-intervention with no change for individuals who were cared for by the non-intervention hospitals (14.9\%). However, while there was an increase in treatment initiation, the proportion with adequate persistence fell from pre- to postintervention from $45.8 \%$ to $40 . \%$ at PFC sites. The reduction in adherence was greater in non-intervention sites. The Swedish four hospitals study used electronic health records to compare the incidence of hip, clinical spine, humerus, radius and pelvis fractures before and after the implementation of different types of FLS [44]. Two hospitals instituted FLSs that included referring identified patients for FRAX and DXA and routine inpatient or community zoledronate or denosumab post-hip fractures. Following 21,083 sentinel fractures, there was an $18 \%$ reduction in recurrent major osteoporotic fractures after the intervention period in FLS hospitals with no change in fractures rate observed in the
non-FLS hospitals. The largest benefit was seen in those aged 82 years and over.

Another study methodology is to use osteoporosis drug therapy rates to predict changes in fracture rates. The Glasgow Fracture Liaison Service, UK, used eight-year audit data to inform a Markov model of secondary fracture prevention using published trials [45]. The model predicted a $7 \%$ reduction in fractures at 5 years. However, all patients were assumed to remain on treatment for 5 years despite no active monitoring programme and a stable 5 year offtreatment was assumed. The Toronto study published costeffectiveness results on treatment initiation and 1 year adherence rates in coordinator vs non-coordinator settings and demonstrated significant cost savings [46]. Again, this study did not directly measure refracture rates, estimated treatment initiation and adherence in the non-coordinator setting and used fracture reduction rates based on clinical trials.

The final method is to use observed fracture rates from patients who did or did not attend a specialist service. The CONCORD study, Australia, demonstrated an $80 \%$ reduction in clinical fractures over 5 years [47]. This difference in clinical fracture rates is unexpected and far exceeds findings from randomised control trials. Using patients who did not attend the specialist clinic as the 'comparator' group would result in a significant immortal time bias. An immortal time bias is where patients are not able to able to experience the outcome during a portion of follow-up as part of the study design. A more general selection bias occurs, as those who attend a PFC service are more likely to be healthier and have fewer co-morbidities. It is also noted that only $20 \%$ of all fragility fracture patients attended the FLS, as those with cognitive impairment and other severe comorbidities were excluded, this limits the generalizability of the service to all fragility fracture patients. An extension of this study design is to compare events post-fracture for patients who attend a hospital with an FLS vs without an FLS. Such studies have shown impressive reductions in refracture rates of $40-56 \%$ [48, 49]. In one study, only 103/515 (20\%) attended the FLS clinic, suggesting any observed differences in fracture rates was unlikely to be driven by the FLS. Attendance was higher in the Dutch study $67.8 \%$ with no difference in refracture rate by attendee status, which is unexpected if the FLS is hypothesised as the cause for fracture reduction [49]. This study also showed a $43 \%$ reduction in mortality in women even though only $50 \%$ of those attending the FLS group were prescribed bisphosphonates, suggest AOM could only partly explain the mortality effect.

Systematic reviews have confirmed that patient/physician education strategies are ineffective $[47,50,51]$ and identified critical issues in current literature such as using treatment initiation as the primary outcome [37] (a poor surrogate given the low adherence to therapy); non-contemporary or estimated control data [45, 52]; effect sizes based on 
Fig. 2 IOF/FFN/NOF indicator Set

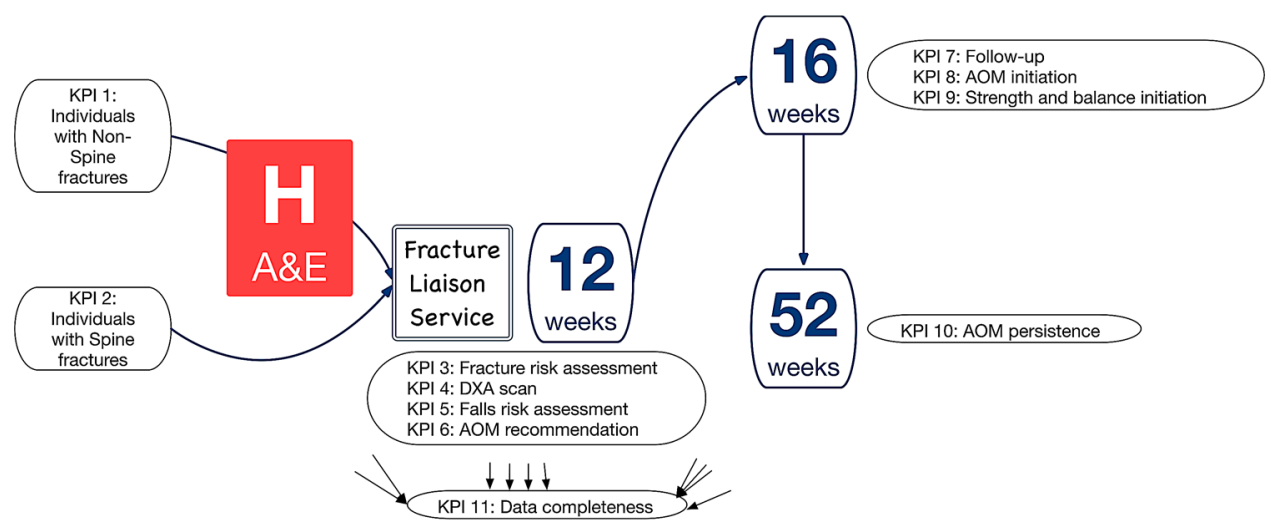

Legend: Adapted from Javaid et al. ${ }^{(59)}$

$\mathrm{AOM}=$ anti-osteoporosis medication randomised controlled trials for the drug [45, 46]; attendee vs non-attendee designs which are subject to significant selection bias, left censoring/immortal time bias [47, 53]. The magnitude of the effect of these biases is evidenced by the reported range of fracture reduction from 7 to $80 \%$. A literature review that included all types of study, irrespective of methodological issues presented above, demonstrated significant increases in BMD testing, treatment initiation, adherence, refracture and mortality [54].

\section{Conclusion}

The rationale for FLS efficacy is sound. There is no equipoise that giving an AOM to the high-risk patient will reduce fracture risk. There is ample supporting evidence for fracture efficacy from RCTs, including in the post-fracture care setting [55]. So, does the rationale for research activities to demonstrate the benefit of an FLS need to be reviewed? The urgent question for patients, clinicians and policymakers is whether the FLS care pathway can deliver the expected benefits from effective secondary prevention in their locality. FLSs often operate in complex local healthcare system relying on the significant interplay between people, equipment, processes and institutions as well as competing priorities, resources and reimbursement. Most complex services require active service improvement to adapt the service to become effective and sustainable based on local healthcare characteristics; one size does not fit all [56]. This requires an evidence base focussing on implementation and quality improvement rather than randomisation and comparison.

Further, an FLS can only be effective if patients engage and adhere to each step of the pathway. Several patent level factors have been identified that need to be addressed by FLSs [57]. To achieve this, FLSs need to be adequately funded both in scale and duration to establish care pathways adapted and optimised to their local healthcare environment, a policy imperative. To achieve this, FLSs need to critically review their performance to identify areas for improvement, develop models of service changes and then analyse the impact of the service change on patient and process outcomes [56]. Quality Improvement capability, capacity and delivery should be included as another specification for FLSs [17]. The availability of data to inform service performance is fundamental to the process of Quality Improvement. Two indicator sets are available that benchmark services: on an organisational level, the IOF Capture the Fracture Best Practice Framework [58]; and on at the patient level, the IOF/FFN/NOF key performance indicator set [59] (Fig. 2). A limitation of these indicators is that they are primarily focussed on effectiveness and do not address efficiency or patient experience, areas for future research.

Providing indicator sets only goes so far to improve performance. Since 2016, the UK FLSDB has been providing real-time performance data for participating FLSs [60, 61], which has resulted in modest improvements. International calls to action and patient charters have been used to increase political and patient awareness. In June 2020, the ambitious Capture the Fracture Partnership was launched to bring together global expertise in secondary prevention across pillars of policy, coalitions, mentorship, scalable solutions and digital tools (Fig. 3). The Capture the Fracture ${ }^{\circledR}$ partnership, between the International Osteoporosis Foundation, the University of Oxford, Amgen and UCB, aims to support the broader implementation of FLS and other PFC related programs, to reduce the incidence of hip and vertebral fractures due to osteoporosis by $25 \%$ by the year 2025. Further academic work should focus on providing the evidence for optimising political prioritisation, local funding and sustainable delivery of effective and efficient FLSs and other PFC models with good patient experience. Hence, 
Fig. 3 The capture the fracture partnership structure

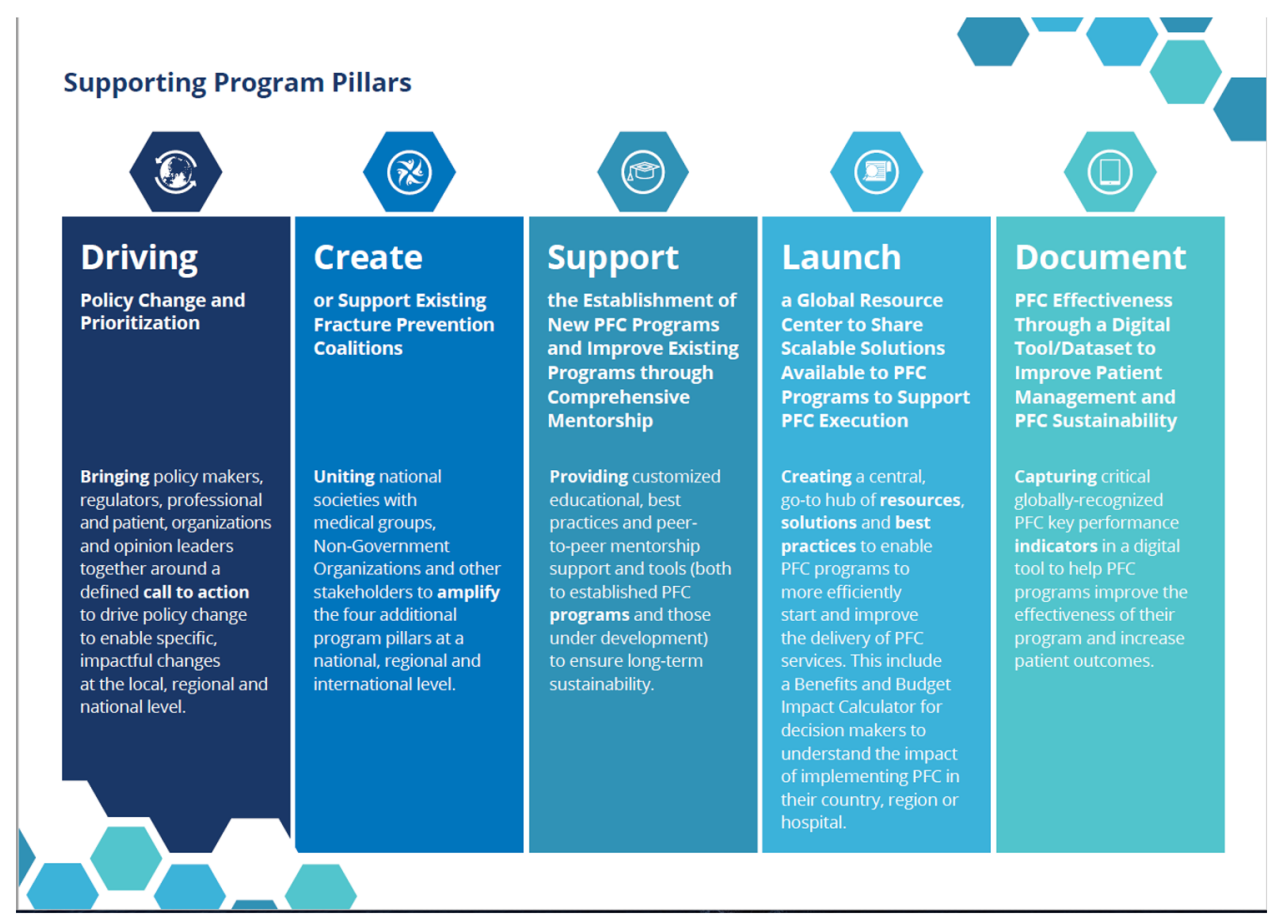

every patient after a fragility fracture receives secondary fracture prevention management to maintain physical and mental health, independence and dignity.

Funding This work was not supported by any external funding.

\section{Declarations}

Conflict of interest Unrelated to this piece of work, Dr Javaid has received over the last 5 years reimbursement for advisory boards, consultancy and speaker fees from Amgen, Consilient Health, Kyowa Kirin Hakin, UCB and Abbvie.

Statement of human and animal rights This study does not contain any studies with animals performed by any of the authors and complies with guidelines for human studies.

Informed consent For this type of study formal consent is not required.

Open Access This article is licensed under a Creative Commons Attribution 4.0 International License, which permits use, sharing, adaptation, distribution and reproduction in any medium or format, as long as you give appropriate credit to the original author(s) and the source, provide a link to the Creative Commons licence, and indicate if changes were made. The images or other third party material in this article are included in the article's Creative Commons licence, unless indicated otherwise in a credit line to the material. If material is not included in the article's Creative Commons licence and your intended use is not permitted by statutory regulation or exceeds the permitted use, you will need to obtain permission directly from the copyright holder. To view a copy of this licence, visit http://creativecommons.org/licenses/by/4.0/.

\section{References}

1. Kanis J, McCloskey E, Harvey NC et al (2018) Broken bones, broken lives: a roadmap to solve the fragility fracture crisis in Europe. Broken bones, broken lives: http://share.iofbonehealth. org/EU-6-Material/Reports/IOF\%20Report_EU.pdf: International Osteoporosis Foundation.

2. Klotzbuecher CM, Ross PD, Landsman PB et al (2000) Patients with prior fractures have an increased risk of future fractures: a summary of the literature and statistical synthesis. J Bone Miner Res 15:721-739

3. Kanis JA, Johnell O, De Laet C et al (2004) A meta-analysis of previous fracture and subsequent fracture risk. Bone 35:375-382

4. Marsh D, Akesson K, Beaton DE et al (2011) Coordinator-based systems for secondary prevention in fragility fracture patients. Osteoporos Int 22:2051-2065

5. Klop C, Gibson-Smith D, Elders PJ et al (2015) Anti-osteoporosis drug prescribing after hip fracture in the UK: 2000-2010. Osteoporos Int 26:1919-1928

6. Skjødt MK, Khalid S, Ernst M et al (2020) Secular trends in the initiation of therapy in secondary fracture prevention in Europe: a multi-national cohort study including data from Denmark, Catalonia, and the United Kingdom. Osteoporos Int 31:1535-1544

7. Akesson K, Marsh D, Mitchell PJ et al (2013) Capture the fracture: a best practice framework and global campaign to break the fragility fracture cycle. Osteoporos Int 24:2135-2152

8. Javaid MK, Kyer C, Mitchell PJ et al (2015) Effective secondary fracture prevention: implementation of a global benchmarking of clinical quality using the IOF capture the fracture(R) best practice framework tool. Osteoporos Int 26:2573-2578

9. Eisman JA, Bogoch ER, Dell R et al (2012) Making the first fracture the last fracture: ASBMR task force report on secondary fracture prevention. J Bone Miner Res 27:2039-2046. https://doi. org/10.1002/jbmr.1698

10. Lems WF, Dreinhofer KE, Bischoff-Ferrari H et al (2017) EULAR/EFORT recommendations for management of patients 
older than 50 years with a fragility fracture and prevention of subsequent fractures. Ann Rheum Dis 76:802-810

11. Geusens P, Eisman JA, Singer A et al (2019) Fracture liaison service. In: Bilezikian JP (ed) Primer in the metabolic bone diseases and disorders of mineral metabolism. John Wiley \& Sons INc, pp 405-411

12. Kanis JA, Cooper C, Rizzoli R et al (2019) Executive summary of European guidance for the diagnosis and management of osteoporosis in postmenopausal women. Aging Clin Exp Res 31:15-17

13. De Vincentis A, Behr AU, Bellelli G et al (2020) Management of hip fracture in the older people: rationale and design of the Italian consensus on the orthogeriatric co-management. Aging Clin Exp Res 32:1393-1399

14. Sanli I, van Helden SH, Ten Broeke RHM et al (2019) The role of the fracture liaison service (FLS) in subsequent fracture prevention in the extreme elderly. Aging Clin Exp Res 31:1105-1111

15. McLellan A, Reid DM, Forbes K, Reid R, Campbell C, Gregori A, et al. Effectiveness of Strategies for the Secondary Prevention of Osteoporotic Fractures in Scotland: CEPS: 99/03. NHS Quality Improvement Scotland 2004. http://www.healthcareimprovemen tscotland.org/his/idoc.ashx?docid=ef9ef57b-be5a-4677-9e26ff941bd01dc1\&version=-1

16. Gallacher SJ (2005) Setting up an osteoporosis fracture liaison service: background and potential outcomes. Best Pract Res Clin Rheumatol 19:1081-1094

17. Gallacher S, Alexander S, Beswetherick N, Carr W, Durber A, Gittoes N et al (2019) Effective secondary prevention of fragility fractures: clinical standards for fracture liaison services. Royal Osteoporosis Society. https://theros.org.uk/media/1eubz33w/rosclinical-standards-for-fracture-liaison-services-august-2019.pdf

18. Black DM, Cummings SR, Karpf DB et al (1996) Randomised trial of effect of alendronate on risk of fracture in women with existing vertebral fractures. Fracture intervention trial research group. Lancet 348:1535-1541

19. Reginster J, Minne HW, Sorensen OH et al (2000) Randomized trial of the effects of risedronate on vertebral fractures in women with established postmenopausal osteoporosis. Vertebral efficacy with risedronate therapy (VERT) study group. Osteoporos Int 11:83-91

20. Meunier PJ, Roux C, Seeman E et al (2004) The effects of strontium ranelate on the risk of vertebral fracture in women with postmenopausal osteoporosis. N Engl J Med 350:459-468

21. Chesnut CH 3rd, Skag A, Christiansen C et al (2004) Effects of oral ibandronate administered daily or intermittently on fracture risk in postmenopausal osteoporosis. J Bone Miner Res 19:1241-1249

22. Cummings SR, San Martin J, McClung MR et al (2009) Denosumab for prevention of fractures in postmenopausal women with osteoporosis. N Engl J Med 361:756-765

23. Black DM, Delmas PD, Eastell R et al (2007) Once-yearly zoledronic acid for treatment of postmenopausal osteoporosis. N Engl J Med 356:1809-1822

24. Miller PD, Hattersley G, Riis BJ et al (2016) Effect of abaloparatide vs placebo on new vertebral fractures in postmenopausal women with osteoporosis: a randomized clinical trial. JAMA 316:722-733

25. Cosman F, Crittenden DB, Adachi JD et al (2016) Romosozumab treatment in postmenopausal women with osteoporosis. N Engl J Med 375:1532-1543

26. Hawley S, Leal J, Delmestri A et al (2016) Anti-osteoporosis medication prescriptions and incidence of subsequent fracture among primary hip fracture patients in England and wales: an interrupted time-series analysis. J Bone Miner Res 31:2008-2015

27. Freemantle N, Cooper C, Diez-Perez A et al (2013) Results of indirect and mixed treatment comparison of fracture efficacy for osteoporosis treatments: a meta-analysis. Osteoporos Int 24:209-217

28. Leslie WD, Schousboe JT, Morin SN et al (2020) Fracture risk following high-trauma versus low-trauma fracture: a registry-based cohort study. Osteoporos Int 31:1059-1067

29. Mackey DC, Lui LY, Cawthon PM et al (2007) High-trauma fractures and low bone mineral density in older women and men. JAMA 298:2381-2388

30. Mackey DC, Black DM, Bauer DC et al (2011) Effects of antiresorptive treatment on nonvertebral fracture outcomes. J Bone Miner Res 26:2411-2418

31. Roux C, Briot K (2017) Imminent fracture risk. Osteoporos Int 28:1765-1769

32. Kanis JA, Johansson H, Oden A et al (2018) Characteristics of recurrent fractures. Osteoporos Int 29:1747-1757

33. Pinedo-Villanueva R, Charokopou $M$ et al (2019) Imminent fracture risk assessments in the UK FLS setting: implications and challenges. Arch Osteoporos 14:12

34. Kendler DL, Marin F, Zerbini CAF et al (2018) Effects of teriparatide and risedronate on new fractures in post-menopausal women with severe osteoporosis (VERO): a multicentre, double-blind, double-dummy, randomised controlled trial. Lancet 391:230-240

35. Saag KG, Petersen J, Brandi ML et al (2017) Romosozumab or alendronate for fracture prevention in women with osteoporosis. N Engl J Med 377:1417-1427

36. Inderjeeth CA, Chan K, Kwan K et al (2012) Time to onset of efficacy in fracture reduction with current anti-osteoporosis treatments. J Bone Miner Metab 30:493-503

37. Majumdar SR, Johnson JA, McAlister FA et al (2008) Multifaceted intervention to improve diagnosis and treatment of osteoporosis in patients with recent wrist fracture: a randomized controlled trial. CMAJ 178:569-575

38. Majumdar SR, McAlister FA, Johnson JA et al (2018) Comparing strategies targeting osteoporosis to prevent fractures after an upper extremity fracture (C-STOP Trial): a randomized controlled trial. J Bone Miner Res 33:2114

39. McAlister FA, Ye C, Beaupre LA et al (2019) Adherence to osteoporosis therapy after an upper extremity fracture: a pre-specified substudy of the C-STOP randomized controlled trial. Osteoporos Int 30:127-134

40. Dell R, Greene D, Schelkun SR et al (2008) Osteoporosis disease management: the role of the orthopaedic surgeon. J Bone Joint Surg Am 90:88-194

41. Hawley S, Javaid MK, Prieto-Alhambra D et al (2016) Clinical effectiveness of orthogeriatric and fracture liaison service models of care for hip fracture patients: population-based longitudinal study. Age Ageing 45:236-242

42. Drew S, Judge A, Cooper C et al (2016) Secondary prevention of fractures after hip fracture: a qualitative study of effective service delivery. Osteoporos Int 27:1719

43. Beaton DE, Mamdani M, Zheng $\mathrm{H}$ et al (2017) Improvements in osteoporosis testing and care are found following the wide scale implementation of the Ontario fracture clinic screening program: an interrupted time series analysis. Medicine 96:e9012

44. Axelsson KF, Johansson H, Lundh D et al (2020) Association between recurrent fracture risk and implementation of fracture liaison services in four Swedish hospitals: a cohort study. J Bone Miner Res 35:1216-1223

45. McLellan AR, Wolowacz SE, Zimovetz EA et al (2011) Fracture liaison services for the evaluation and management of patients with osteoporotic fracture: a cost-effectiveness evaluation based on data collected over 8 years of service provision. Osteoporos Int 22:2083-2098

46. Sander B, Elliot-Gibson V, Beaton DE, Bogoch ER, Maetzel A (2008) A coordinator program in post-fracture osteoporosis 
management improves outcomes and saves costs. J Bone Joint Surg Am 90:1197-1205

47. Lih A, Nandapalan H, Kim M et al (2011) Targeted intervention reduces refracture rates in patients with incident non-vertebral osteoporotic fractures: a 4 year prospective controlled study. Osteoporos Int 22:849-858

48. Nakayama A, Major G, Holliday E et al (2015) Evidence of effectiveness of a fracture liaison service to reduce the re-fracture rate. Osteoporos Int 27:873

49. Huntjens KM, van Geel TA, van den Bergh JP et al (2014) Fracture liaison service: impact on subsequent nonvertebral fracture incidence and mortality. J Bone Joint Surg Am 96:e29

50. Sale JE, Beaton D, Posen J et al (2011) Systematic review on interventions to improve osteoporosis investigation and treatment in fragility fracture patients. Osteoporos Int 22:2067-2082

51. Ganda K, Puech M, Chen JS et al (2013) Models of care for the secondary prevention of osteoporotic fractures: a systematic review and meta-analysis. Osteoporos Int 24:393-406

52. Dell R (2011) Fracture prevention in Kaiser Permanente Southern California. Osteoporos Int 22:457-460

53. Van der Kallen J, Giles M, Cooper K et al (2014) A fracture prevention service reduces further fractures two years after incident minimal trauma fracture. Int J Rheum Dis 17:195-203

54. Wu CH, Chen $\mathrm{CH}$, Chen $\mathrm{PH}$ et al (2018) Identifying characteristics of an effective fracture liaison service: systematic literature review. Osteoporos Int 29:1023

55. Lyles KW, Colon-Emeric CS, Magaziner JS et al (2007) Zoledronic acid and clinical fractures and mortality after hip fracture. N Engl J Med 357:1799-1809
56. Berwick DM (1996) A primer on leading the improvement of systems. BMJ 312:619-622

57. van den Berg P, van Haard PMM, Geusens PP et al (2019) Challenges and opportunities to improve fracture liaison service attendance: fracture registration and patient characteristics and motivations. Osteoporos Int 30:1597-1606

58. Akesson K, Marsh D, Mitchell PJ et al (2013) Capture the fracture: a global campaign to break the fragility fracture cycle. Osteoporos Int 24:2135

59. Javaid MK, Sami A, Lems W et al (2020) A patient-level key performance indicator set to measure the effectiveness of fracture liaison services and guide quality improvement: a position paper of the IOF Capture the Fracture Working Group, National Osteoporosis Foundation and Fragility Fracture Network. Osteoporos Int 31:1193

60. Boulton C, Gallagher C, Rai S et al (2017) Fracture liaison service database (FLS-DB) clinical audit. In: Programme FaFFA (ed) FLS forward: identifying high-quality care in the NHS for secondary fracture prevention. Royal Collge of Physicians, London, pp 1-70

61. Javaid MK, Vasilakis N, Dickinson R et al (2018) Fracture liaison service database annual report december 2018: achieving effective service delivery by fracture liaison services London. Royal College of Physicians

Publisher's Note Springer Nature remains neutral with regard to jurisdictional claims in published maps and institutional affiliations. 